\title{
State Policy and Classroom Performance: Mathematics Reform in California
}

David Cohen

Heather Hill

Follow this and additional works at: https://repository.upenn.edu/cpre_policybriefs

Part of the Curriculum and Instruction Commons, Educational Methods Commons, Education Policy Commons, Elementary Education and Teaching Commons, and the Science and Mathematics Education Commons

\section{Recommended Citation}

Cohen, David and Hill, Heather. (1998). State Policy and Classroom Performance: Mathematics Reform in California. CPRE Policy Briefs.

Retrieved from https://repository.upenn.edu/cpre_policybriefs/10

View on the CPRE website.

This paper is posted at ScholarlyCommons. https://repository.upenn.edu/cpre_policybriefs/10

For more information, please contact repository@pobox.upenn.edu. 


\title{
State Policy and Classroom Performance: Mathematics Reform in California
}

\begin{abstract}
In the early 1990's many states tried to devise more robust and coherent instructional policies, in efforts to make teaching and learning more thoughtful and demanding. Policymakers and reformers pressed teachers to help students understand mathematical concepts, to interpret serious literature, to write creatively about their own ideas and experiences, and to converse thoughtfully about history and social science. But these efforts to reform instruction encountered skepticism about the link between policy and pedagogy. Skeptics ask if it is reasonable to expect state policies to steer teaching and learning sharply away from long-established conventional practice, noting that previous efforts to change practice on a large scale had failed.
\end{abstract}

As instructional policy moved to the top of many state education agendas in the late 1990s, interest in the relations between policy and practice has grown. In this issue of CPRE Policy Briefs, we report encouraging findings from an important study that addresses these relationships. We use data from a 1994 survey of California elementary school teachers to probe the classroom effects of state efforts to reform mathematics teaching and learning in California. We report that policy changes did lead both to changed classroom practice and to improved student performance.

In this brief, we develop a rudimentary model of the relationship between policy and practice. Student achievement is the ultimate dependent measure; teachers' reported classroom practice in mathematics is an influence on achievement, but practice also is a measure of the effects of teachers' learning opportunities about new math curriculum. We present results which show that teachers' learning opportunities influenced their practice, and that both teachers' learning opportunities and their practice influenced students' mathematics achievement. The results suggest that teachers' practice can change in ways that favorably influence student achievement, and that policy can play an important role in making those changes possible.

We begin with a review of the California reform, briefly describe the research approach, and then discuss the major findings.

Disciplines

Curriculum and Instruction | Educational Methods | Education Policy | Elementary Education and Teaching I Science and Mathematics Education

Comments

View on the CPRE website. 


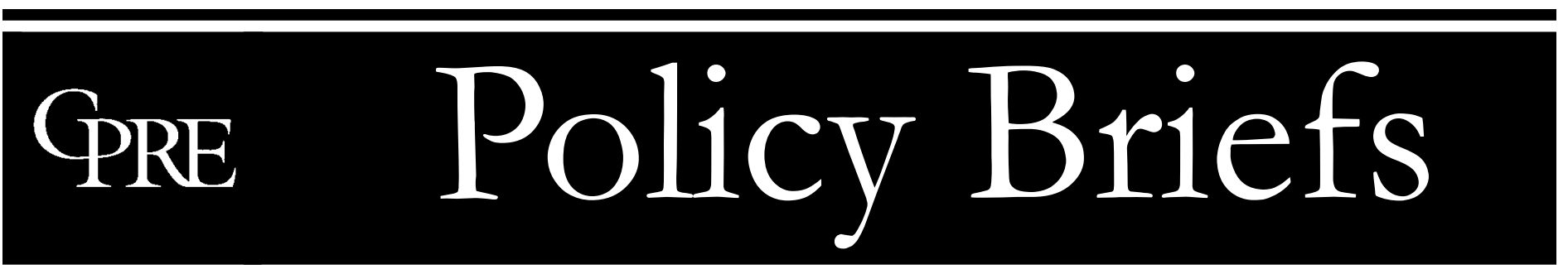

Reporting on issues in education reform

Graduate School of Education • • University of Pennsylvania • RB-23-January 1998

\title{
State Policy and Classroom Performance: Mathematics Reform in California
}

\author{
by David K. Cohen and Heather C. Hill
}

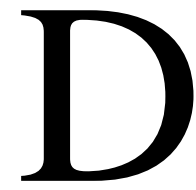
uring the last decade many states have tried to devise more robust and coherent instructional policies, in efforts to make teaching and learning more thoughtful and demanding. Policymakers and reformers have pressed teachers to help students understand mathematical concepts, to interpret serious literature, to write creatively about their own ideas and experiences, and to converse thoughtfully about history and social science. But these efforts to reform instruction have encountered skepticism about the link between policy and pedagogy. Skeptics ask if it is reasonable to expect state policies to steer teaching and learning sharply away from long-established conventional practice, noting that previous efforts to change practice on a large scale have failed.

As instructional policy has moved to the top of many state education agendas in the past ten to fifteen years, interest in the relations between policy and practice has grown. In this issue of CPRE Policy Briefs, we report encouraging findings from an important study that addresses these relationships. We use data from a 1994 survey of California elementary school teachers to probe the classroom effects of state efforts to reform mathematics teaching and learning in California. We report that policy changes did lead both to changed classroom practice and to improved student performance.
In this brief, we develop a rudimentary model of the relationship between policy and practice. Student achievement is the ultimate dependent measure; teachers' reported classroom practice in mathematics is an influence on achievement, but practice also is a measure of the effects of teachers' learning opportunities about new math curriculum. We present results which show that teachers' learning opportunities influenced their practice, and that both teachers' learning opportunities and their practice influenced students' mathematics achievement. The results suggest that teachers' practice can change in ways that favorably influence student achievement, and that policy can play an important role in making those changes possible.

We begin with a review of the California reform, briefly describe the research approach, and then discuss the major findings.

\section{School Reform in California}

Like other states in the 1980s, California sought to improve student achievement by redesigning state policies and other mechanisms specific to instructional policy, including student curriculum, assessments, and professional development. The goal was to change classroom practice across the state, and thus improve student performance. These effects would depend in considerable part on professional learning, for the policies could not change 
practice unless teachers learned new views of mathematics. Teachers' learning opportunities thus were a key policy instrument.

The California Department of Education took the first step in 1985 when it issued a new Mathematics Framework; the endeavor continues today, though much modified. The 1985 Mathematics Framework called for more intellectually ambitious instruction, for more engaging mathematics work for students, for teachers to open discourse about math in their classrooms and to pay more attention to students' mathematical ideas, and for teachers to help students understand math instead of just memorizing facts and operations. Although officially only advisory to local districts, the Mathematics Framework was a central part of state instructional policy.

Shortly after issuing the new Mathematics Framework, the California State Board of Education attempted to use textbook adoption as a policy instrument. State approval carries great weight with local districts because they receive state aid for using approved texts. ${ }^{1}$ The State Board initially rejected most math textbooks because they did not conform to the new Mathematics Framework. After much debate, partial revision of some texts, and political conflict, the State
Board approved most of them. Unhappy with the limited changes in texts, state officials decided that textbook revision might not be the best means to encourage reform.

State officials began to stimulate the development of other curriculum materials-especially topic-centered teaching modules called "replacement units." These modules would support changed mathematics teaching, each focusing on a few weeks of classwork. State Department of Education staffers also encouraged teacher professional development centered on the reforms. For the new instructional ideas to be taken seriously, teachers and other educators would have to learn a great deal. Moreover, the Mathematics Framework offered only general guidance to teachers, so its effective use would heavily depend on teachers' knowledgeable use of the guidance.

The California Department of Education also used its student assessment system as another means to change teaching practice, and devoted considerable effort to revising the tests and aligning them with the Mathematics Framework. Some reformers were uneasy about testing, but others assumed that new tests could help. Once the state began testing students on the new mathematical content and methods, they reasoned, test scores would drop because the material would be unfamiliar and more difficult. Teachers and the public would notice the lower scores, which would generate pressure for better results. Teachers would respond to the pressure by paying attention to the new tests and changing instruction.

The California Department of Education had difficulty revising the tests in part because it was a formidable task, in part because of disagreements between the State Superintendent of Public Instruction and the Governor, and in part because of the Superintendent's legal difficulties and ultimate departure. The revisions were finally completed and the new tests, the California Learning Assessment System (CLAS), were administered in 1993 and 1994. Just as state education leaders had predicted, scores were lower and the public took note. But a storm of protest erupted after the 1993 test results were published: scores were generally low, and a technical panel gave low grades to features of the assessment and its administration. Some modifications were made for the 1994 administration of the CLAS tests, partly in response to the outcry over low scores, but it was too late. The entire enterprise came under question. Some criticized the new tests because, they claimed, they paid little attention to the "basics" and instead encouraged "critical thinking" or

\section{About CPRE Briefs}

CPRE briefs are published occasionally by the Consortium for Policy Research in Education. The study reported in this issue was supported by a grant (No. OERI-R308A60003) to the Consortium for Policy Research in Education (CPRE), from the National Institute on Educational Governance, Finance, Policymaking and Management, Office of Educational Research and Improvement, U.S. Department of Education, and by grants from the Carnegie Corporation of New York and The Pew Charitable Trusts to Michigan State University. The survey reported herein was supported by the National Science Foundation. The views expressed in this publication are those of its authors and are not necessarily shared by the U. S. Department of Education, the Carnegie Corporation, the Pew Charitable Trusts, the National Science Foundation, Michigan State University, the Consortium, or its institutional members. 
"outcomes-based education." Others raised questions about the technical quality of the test, its administration, reporting, and analysis, especially the "subjectivity" of items and scoring. The Governor, who had wanted a testing program that produced individual student scores rather than school average scores, canceled the testing program.

California's instructional reforms continue, but no test linked to the Mathematics Framework now exists, and the Framework has just been revised amidst continuing controversy about "critical thinking" and the "basics."

\section{The CPRE Study}

The research reported here began roughly a decade ago with a research group at Michigan State University. The researchers wanted to learn how teachers responded to the wave of ambitious state instructional policies in California and several other states, and to use this knowledge to improve understanding of policymaking and implementation. Members of the research group studied documents, visited elementary schools and classrooms in three California school districts, and followed the same schools and teachers for four or five years. ${ }^{2}$ The researchers also followed developments in state and district offices by interviewing many state and district administrators and reformers, and by studying efforts to improve teacher knowledge and skills in various professional development projects.

As the researchers studied classrooms and mathematics teaching in California, they saw that the reforms required extensive learning. The reforms could not be enacted unless educators, parents, and policymakers revised much of their knowledge of both mathematics and instruction, and unless educators developed new ways to teach the subject. Hence, implementation of these reforms would require learning opportunities that did not exist in 1985 . $^{3}$ California's mathematics instructional policy entailed a re-education program for teachers.

If implementation of the new Mathematics Framework was partly a matter of teacher learning, and if most teachers could not teach themselves what they did not know, then some agency or agencies would have to teach the teachers. That led the Michigan State research team to explore several issues: What learning opportunities were available to teachers and others responsible for implementing the new Mathematics Framework? What mathematics content and pedagogies were teachers taught? Was there any connection between teachers' learning opportunities and practice?

To answer these and other questions, the research team supplemented the indepth studies of California classrooms and teachers with a one-time survey of 1,000 teachers, sampled to represent the population of second through fifth grade elementary school teachers in California. ${ }^{4}$ Questions included teachers' opportunities to learn about the mathematics reforms, about their mathematics teaching practice and its relation to some of the dimensions advocated by the new Framework, and how their practice followed or varied from conventional practice.

\section{Finding One: Learning Opportunities Varied Among Teachers}

Teachers reported three different types of learning opportunities: study of specific math curriculum materials that had been created to advance the reforms; study of special topics and issues related to the mathematics reform; and participation in reform networks and activities. Table 1 presents evidence of the time teachers spent in different types of learning opportunities. Teachers were asked to estimate how much time they invested in mathematics-related professional development activities within the past year.

The workshops included in Section A at the top of Table 1 focused on the new mathematics curriculum for students. The Marilyn Burns Institutes concentrated on teaching specific math topics, while the replacement unit workshops (Ms. Burns also developed several of these) focused on curriculum modules designed to be consistent with the mathematics reforms, and centered on specific topics (such as fractions) or sets of topics. ${ }^{5}$ Mathematics educators devised the high-quality topiccentered replacement units to be coherent and comprehensive in the exploration of mathematical topics, and to support teacher and student learning.

The workshops included in Section B at the bottom of Table 1-EQUALS, Family Math, and cooperative learning —were loosely related to the goals of the Mathematics Framework, but were not focused directly on the student mathematics curriculum. EQUALS addresses gender, linguistic, class and racial inequalities in math 


\section{Table 1 \\ Teachers' Learning Opportunities}

California elementary school teachers were asked in which of the following mathematics-related activities they participated during the past year and how much total time they spent in each activity (for example, four two-hour meetings would equal one day).

\begin{tabular}{|lccccc|}
\hline Mathematics-Related Activity & None & $\begin{array}{c}1 \text { day } \\
\text { or less }\end{array}$ & $\begin{array}{c}2 \text { to } 6 \\
\text { days }\end{array}$ & $\begin{array}{c}1 \text { to } 2 \\
\text { weeks }\end{array}$ & $\begin{array}{c}\text { More than } \\
2 \text { weeks }\end{array}$ \\
\hline A. Student Curriculum-Centered Workshops & & & & & .3 \\
Marilyn Burns & 83.2 & 9.8 & 5.3 & 1.3 & 2.5 \\
Mathematics Replacement Units & 58.9 & 22.7 & 14.2 & 1.7 & .2 \\
B. Special Topics/lssues Workshops & & & & .9 & .3 \\
EQUALS & 96.5 & 2.4 & 1.9 & 1.8 \\
Family Math & 81.7 & 12.9 & 4.3 & .8 & 1.7 \\
Cooperative Learning & 54.5 & 28.9 & 13.7 & 1.8 & .3 \\
\hline
\end{tabular}

Note: Numbers are percentages of respondents selecting that category, weighted to represent statewide population. Missing data assumed to indicate no participation in the mathematics-related activities.

classes; Family Math helps teachers to involve parents in their children's math learning. Cooperative learning workshops come in many varietiessome, for example, focus on detracking - but all encourage students to learn together. ${ }^{6}$

Two-thirds of the teachers responding to the survey reported participating in at least one of the five mathematicsrelated professional development activities listed in Table 1, in the year just prior to the survey. The breadth of these professional development opportunities, however, was not matched by their depth.

Table 1 shows that most teachers reported spending only nominal amounts of time in either type of professional development activity. Of the teachers who reported attending one of the workshops in the past year, roughly half indicated they spent one day or less than one day in the mathematics-related activity. Appro- ximately 35 percent reported spending between two and six days. A smaller fraction of those who attended the workshops, and a very small fraction of the entire sample, attended workshops lasting one week or longer.

This finding accords with other reports about professional development: a teacher's opportunity for professional development typically consists of a few days each year. ${ }^{7}$ Few California teachers found rich learning opportunities. Most encountered the mathematics reforms in conventional settings - in a day-long or shorter oneshot introduction to a particular instructional technique or curriculum.

Another way of placing these numbers in context is to see how they relate to teachers' other opportunities for learning about California's Mathematics Framework. In addition to student curriculum-centered or special topics/ issues specific workshops, teachers could have engaged in other activities designed to familiarize them with the reform, such as participating in reform networks, attending meetings of mathematics teachers, or serving on committees. Table 2 shows that few teachers did so. Fewer than six in every hundred teachers responding to the survey reported attending a national mathematics teacher association meeting; only twelve or thirteen of every hundred teachers reported participating in other state or regional meetings, teaching local workshops, or serving on local curriculum committees. Teacher contact with the reforms via these leadership activities was less frequent than their contact through more conventional professional development avenues.

In addition to asking teachers about their learning opportunities in the year before the survey, we also asked whether they had had opportunities to learn about the new mathematics standards at all in their careers. Sixtyfive percent of teachers responding to 
the survey reported that they had attended school or district workshops related to the new mathematics standards; 45 percent said they had been given time to attend off-site workshops or conferences related to the standards. Nearly seven out of ten teachers reported participating in one or both of these two activities. These are only general measures-we have no evidence of whether these other learning opportunities were long or short, were focused on specific problems or general principles, or were in innovative or conventional formats.

Tables 1 and 2 could be seen as evidence that California policymakers and reformers wanted to leverage deep changes in mathematics instruction with only modest investments. But recent research suggests that altering the core elements of teaching requires extended learning opportunities for teachers, generous support from peers and mentors, and opportunities to practice, reflect, critique, and practice again. ${ }^{8}$ Such opportunities and support were unlikely in the brief professional development activities of most California teachers.

But the two tables also offer evidence that some reformers undertook a novel approach: some teachers' professional development was grounded in the improved student curriculum that state policymakers had encouraged. Most professional development is not grounded in student curriculum. By comparing the two types of mathematics-related activities presented in Table 1, we could ask a central question: Did teachers who attended the student curriculumcentered workshops shown in Table 1 report different kinds of practice than those who attended the special topics/ issues workshops?

\section{Finding Two: Certain \\ Types of Learning Opportunities \\ Influenced Practice}

Teachers who had opportunities to learn about student math curriculum reported more of the kind of practice supported by the Framework. This central finding suggests that the content of teachers' professional development can make a difference in their classroom practice. Table 3 (see page 6) presents evidence of the impact that workshop content had on teachers' reports of conventional and Framework mathematics instructional practices. Here and elsewhere, we used regression to sort out the effects from different influences on teachers' reported practices, and included three control variables-teachers' familiarity with reform; their predisposition toward mathematics reform; and a dummy variable capturing teacher attendance at reform workshops in years prior to the one measured by 'student curriculum' and 'special topics.' 9

As these regressions show, those who learned about student math curriculum were more likely to report such practices as having students discuss different ways to solve particular problems, having them work on extended individual projects, or using problems with multiple solutions. The average teacher who attended a Marilyn Burns or replacement unit workshop reported more such practice (nearly three-quarters of a standard deviation) than the average teacher who did not attend those workshops. Moreover, the relationship works in both directions. Teachers who reported attendance at either a Marilyn Burns or replacement unit workshop reported fewer conventional practices like worksheets (about four-tenths of a standard deviation) than teachers who did not attend them. These student curriculumcentered learning opportunities seem
Table 2

Teacher Participation in Reform Networks and Leadership Roles

\begin{tabular}{|lcc|}
\hline Network or Leadership Role & $\begin{array}{c}\text { Percent that did } \\
\text { participate }\end{array}$ & $\begin{array}{c}\text { Percent that did } \\
\text { not participate }\end{array}$ \\
\hline $\begin{array}{l}\text { Attended a national mathematics } \\
\text { teacher association meeting }\end{array}$ & 5.7 & 94.5 \\
$\begin{array}{l}\text { Attended a state mathematics teacher } \\
\text { association meeting, including } \\
\text { California Mathematics Council } \\
\text { Affiliates }\end{array}$ & 12.3 & 85.1 \\
$\begin{array}{l}\text { Taught an in-service workshop or } \\
\text { course in mathematics or mathematics } \\
\text { teaching }\end{array}$ & 13.6 & 83.5 \\
$\begin{array}{l}\text { Served on a district mathematics } \\
\text { curriculum committee }\end{array}$ & 13.7 & 84.6 \\
\hline
\end{tabular}

Note: Teachers were asked to report only for the year prior to the survey. Numbers are percentages of respondents selecting that category, weighted to represent statewide population. 
to increase Framework practice and to decrease conventional practice. Teachers did not just add new practices to a conventional core, but also changed that core.

In contrast, workshops not closely tied to the student mathematics curriculum appear to be unrelated both to the kinds of practices California policymakers wished to see in schools and to the conventional practices (such as worksheets and computational tests) they were trying to change. ${ }^{10} \mathrm{We}$ suspect this is because the special topics/issues workshops, though consistent with the state Mathematics Framework in some respects, are focused less on the mathematics teaching practices that are central to instruction than on other matters which, while relevant to instruction, do not chiefly address mathematical content. The special topics/issues workshops may be useful for some purposes, but are likely to be peripheral to mathematics teaching-for example, incorporating cooperative learning groups-rather than changing core beliefs and practices about mathematics and its teaching.

The kind of learning that took place in the Marilyn Burns and replacement unit workshops-learning about the mathematics that their students would study and learning something about teaching and learning that mathematics—differs quite sharply from most professional development. Most teacher professional development seems to be generic ("classroom management," for example) or peripheral to subject matter (such as "using math manipulatives"). Generic and peripheral professional development do not have deep connections to central topics in school subjects. ${ }^{11}$ In the 1980s, there was a modest move away from generic pedagogy workshops and toward subject-specific workshops, such as cooperative learning for mathematics, that several observers considered an improvement. ${ }^{12}$ Our survey results, however, suggest that teachers' learning opportunities may

\begin{tabular}{|c|c|c|c|c|}
\hline \multicolumn{5}{|c|}{$\begin{array}{c}\text { Table } 3 \\
\begin{array}{c}\text { Associations Between Teachers' Learning Opportunities } \\
\text { and Teachers' Practice }\end{array}\end{array}$} \\
\hline & \multicolumn{2}{|c|}{ Curriculum Only Equations } & \multicolumn{2}{|c|}{$\begin{array}{c}\text { Curriculum Plus Time } \\
\text { Equations }\end{array}$} \\
\hline & $\begin{array}{l}\text { Conventional } \\
\text { Practice }\end{array}$ & $\begin{array}{l}\text { Framework } \\
\text { Practice }\end{array}$ & $\begin{array}{l}\text { Conventional } \\
\text { Practice }\end{array}$ & $\begin{array}{l}\text { Framework } \\
\text { Practice }\end{array}$ \\
\hline Intercept & $1.6^{*}$ & $1.78^{*}$ & $1.56^{*}$ & $1.83^{*}$ \\
\hline Student Curriculum-Centered Workshop & $-0.30^{*}$ & $0.54^{*}$ & $-0.15^{\star \star}$ & $0.36^{*}$ \\
\hline Time in Student Curriculum-Centered Workshop & & & $-0.08^{*}$ & $0.09^{*}$ \\
\hline Special Topics/lssues Workshop & 0.02 & 0.01 & -0.03 & 0.04 \\
\hline Time in Special Topics/Issues Workshop & & & 0.05 & -0.04 \\
\hline Previous Framework Learning & 0.02 & $0.20^{*}$ & 0.02 & $0.21^{*}$ \\
\hline Affect & $-0.21^{*}$ & $0.22^{*}$ & $-0.21^{*}$ & $0.22^{*}$ \\
\hline Familiarity & $-0.85^{*}$ & $0.42^{*}$ & $-0.79^{*}$ & $0.36^{\star *}$ \\
\hline R2 (adjusted) & 0.17 & 0.22 & 0.19 & 0.25 \\
\hline
\end{tabular}

Note: Conventional practice includes having students practice or take tests on computational skills or having students work individually on mathematics problems from the textbook or workbook. Framework practice includes having students making conjectures and exploring possible methods to solve a mathematics problem, working in small groups on mathematics problems or working on projects that take several days.

* Indicates significance at $P<.05$ level

** Indicates significance at $P<.10$ level

Estimation by Ordinary Least Squares. 
need to go one level deeper than mere subject specificity. Providing teachers with even more concrete, topicspecific learning opportunities-in fractions, measurement, or geometry-appears to help change mathematics teaching practices. This conjecture is consistent with recent research in cognitive psychology which holds that learning is domainspecific. ${ }^{13}$

\section{Finding Three: The Amount of Professional Development Influenced Practice}

Teachers who spent more time in Marilyn Burns and replacement unit learning situations reported more Framework-related practice and less conventional practice. This result parallels research on students' learning opportunities: the combination of time and content-focus are a potent influence on learning. In contrast, time spent in special topics/issues workshops did not have the same payoff in practice. Even large investments of time in less contentfocused workshops were not associated with more of the practices that reformers want. Again, the effects of the special topics/issues workshops seem tangential to the central classroom issues that are measured by our practice scales and on which the California mathematics reform focused.

\section{Finding Four: CLAS} Tests Had a Limited Influence on Practice

Tests are widely believed to be a significant influence on teaching. The California Learning Assessment System (CLAS) was designed partly
Table 4

Associations Between Teachers' Workshop Learning, Assessment-Related Learning, and Practice Measures

\begin{tabular}{|c|c|c|c|c|}
\hline & \multirow{2}{*}{\multicolumn{2}{|c|}{ Set 1}} & & \\
\hline & & & \multicolumn{2}{|c|}{ Set 2} \\
\hline & $\begin{array}{l}\text { Conventional } \\
\text { Practice }\end{array}$ & $\begin{array}{l}\text { Framework } \\
\text { Practice }\end{array}$ & $\begin{array}{l}\text { Conventional } \\
\text { Practice }\end{array}$ & $\begin{array}{c}\text { Framework } \\
\text { Practice }\end{array}$ \\
\hline Intercept & $1.58^{*}$ & $1.82^{*}$ & $1.62^{*}$ & $1.62^{*}$ \\
\hline $\begin{array}{l}\text { Student Curriculum- } \\
\text { Centered Workshop }\end{array}$ & $-0.16^{*}$ & $0.37^{\star}$ & -0.14 & $0.37^{\star}$ \\
\hline $\begin{array}{l}\text { Time in Student } \\
\text { Curriculum-Centered } \\
\text { Workshop }\end{array}$ & $-0.07^{\star}$ & $0.08^{*}$ & $-0.06^{*}$ & $0.07^{*}$ \\
\hline $\begin{array}{l}\text { Previous Math } \\
\text { Workshop }\end{array}$ & 0.02 & $0.21^{*}$ & 0.06 & $0.23^{*}$ \\
\hline Affect & $-0.21^{*}$ & $0.22^{*}$ & $-0.17^{*}$ & $0.11^{*}$ \\
\hline Familiarity & $-0.84^{*}$ & $0.34^{* *}$ & $-0.61^{*}$ & $0.35^{\star *}$ \\
\hline Learned about CLAS & 0.06 & 0.002 & $0.11^{* *}$ & -0.01 \\
\hline Administered CLAS & -0.004 & $0.14^{*}$ & 0.06 & -0.02 \\
\hline CLAS Useful & & & $-0.14^{*}$ & $0.21^{*}$ \\
\hline R2 (adjusted) & 0.18 & 0.25 & 0.21 & 0.34 \\
\hline
\end{tabular}

* Indicates significance at $P<.05$ level

** Indicates significance at $P<.10$ level

for this purpose. California reformers and educators designed an assessment that would focus on the new conceptions of mathematics and mathematical performance advanced by the state's Mathematics Framework.

Two variables were used to measure teachers' responses to CLAS: for "Learned about CLAS," we asked teachers if they had participated in any activities-such as task development, scoring, pilot testing or staff development-that provided information about the new assessment; and for "Administered CLAS", we asked teachers if they had administered CLAS tests. Approx- imately one-third of the teachers reported that they had learned about CLAS; a third also reported they had administered CLAS. Yet not every teacher who learned about CLAS also administered the CLAS tests, and vice versa. While there was an association between these two variablesteachers who administered the CLAS tests were more likely to have had an opportunity to learn about it-there also was enough variance to enable us to sort out the effects of learning about the test from the effects of actually administering it.

Table 4 shows a statistically significant and positive relationship between teachers administering CLAS and reporting more Framework practice. 
The relationship, however, is quite modest: it is not close in size to the association between student curriculum-centered workshop learning and practice. ${ }^{14}$ In addition, this association between administering CLAS and practice does not decrease teacher reports of conventional practices such as bookwork and computational tests. It appears that any incentive associated with the administration of CLAS only adds new practices to existing conventional practice. In other words, instead of redecorating the whole house, teachers supplemented an existing motif with more stuff-a result that was also clear in our field work. ${ }^{15}$ The other CLAS variable, whether teachers reported they had learned about CLAS, was unrelated to teachers' descriptions of their classroom practice in mathematics. In contrast, teachers who spent extended time in student curriculumcentered workshops reported less conventional practice and more framework-oriented practice.

The modest effect of CLAS administration might disappoint supporters of assessment-based reform because it suggests that the incentives associated with testing alone are not great. It should be noted, however, that the CLAS lasted only two years and published results only at the school level, which may have been insufficient for incentive effects to develop.

\section{Finding Five: CLAS as Learning Opportunity Had Wider Influence on Practice}

Not all teachers who reported administering the CLAS either agreed with the test's orientation or modified their teaching to fit the test. Many teachers who administered the test liked it and used it as a learning opportunity, but others did not. Still others did not administer the test, but reported they had learned new kinds of mathematics and instructional practices in CLAS workshops. The effects of testing on teaching practice were seen among these teachers who considered themselves to be learners about and sympathizers with the CLAS, as captured by the CLAS useful variable in Table 4, Set 2 . This relationship works both ways: teachers in this group reported more framework practices and fewer conventional practices.

Instead of compelling teachers to teach the mathematics to be tested, the CLAS seems to have provided teachers with occasions to observe, think about, and revise mathematics instruction. Some teachers seized the occasion while others ignored it. One teacher, interviewed in a related study, reported:

“...the CLAS test....It was a shock to me. They [students] really did fall apart. It was like, 'Oh! What do I do?' And I realized, I need to look at mathematics differently. You know, I really was doing it the way I had been taught so many years before. I mean, it was so dated. And I began last year, because of the CLAS test the year before, looking to see what other kinds of things were available." 16

This teacher's learning (“...looking to see what other kinds of things were available") and her efforts to change her practice were associated with the incentive created when she noticed that her students "...really did fall apart" when taking the new test. Her students' weak test performance inspired her to help them do better, even before she saw any test results.
Thus, California's use of curriculumaligned assessment did not act as a simple lever to enforce instructional change-perhaps because of its weak external accountability mechanismbut rather as an incentive and resource for teachers to learn. Further, its effects were selective: many teachers who came in contact with the CLAS were stimulated to reevaluate their math instruction, but the test was a resource or incentive only to those who perceived it as such. State reformers shrewdly provided numerous opportunities for those teachers to learn about the assessment and mathematics it contained, including involving a small group of teachers in piloting and scoring the test and encouraging this small group to offer workshops to the wider teacher population. Observers of math reform reported that these learning opportunities consisted of viewing the types of mathematics problems advanced by the Frameworks; examining student responses to those problems closely; and scoring student work based on state rubrics. In other words, participating teachers were exposed to elements of a curriculum on improved math teaching.

\section{Finding Six: Certain Teacher Learning Opportunities Affected Student Achievement}

Our results suggest that links between instructional policy and classroom practice may be expected when teachers' learning opportunities are:

- grounded in the curriculum that students study;

- connected to several elements of instruction (for example, not only curriculum but also assessment); and

- extended in time. 
Such learning opportunities are not common in American education. Professional development has rarely been grounded in the academic content of schooling or in knowledge about student performance. This may explain why so few studies of professional development report connections to teachers' practice, and why so many studies of instructional policy report weak implementation; teachers' work as learners was not tied to the academic content of their students' work.

A critical question remains: Did students of teachers who received professional development centered on student curriculum score higher on the state mathematics assessments?

To explore this question, we merged fourth grade mathematics scores from the 1994 administration of the California Learning Assessment System (CLAS) with the school files in our data set. The CLAS included a good deal of performance-based assessment. To do well, students had to answer adequately a combination of open-ended and multiple-choice items that were designed to tap their understanding of mathematical problems and procedures. State scorers assigned scores from Level-1 to Level-6 based on student proficiency levels; school scores were reported as "percent of students scoring Level-1" and so on. We created an average of these for each school to represent our CLAS dependent variable, with the higher school scores representing a more proficient student body. ${ }^{17}$

Because the California Department of Education reported only school-level scores, we had to compute school averages of all independent variables, including teachers' reports of practice and learning opportunities. The survey sampled only four or fewer teachers per school, so the averages provided only a crude estimate of our independent measures. Therefore, these measures of school engagement with reform are error-filled, that is, they are likely to bias the investigation against finding significant results, because random noise in equations diminishes the effects on affected variables.

We created three additional variables for each school in the sample: a measure of student socio-economic status; a measure of school conditions; and a measure of replacement unit use. ${ }^{18}$ In addition to these three, we continued to use the variables (all averaged for schools) that mark other potential connections between policy and practice, including time spent in certain workshops, ${ }^{19}$ our control for teachers' previous Framework learning experiences, ${ }^{20}$ teachers' reports of Framework practice, and a CLAS Learning Opportunities measure (indicating teacher-reported attendance at a state or district-sponsored opportunity to learn about the new mathematics assessment).

The central issue in this analysis is whether the evidence supports our model of relationships between policy and performance, and whether this relationship is mediated by teachers' practice. Equation 1 in Table 5 shows a modest relationship on the second count: schools in which teachers report classroom practice that is more oriented to the Mathematics Framework have higher average student scores on the fourth grade 1994CLAS, controlling for demographic characteristics of schools. No such relationship was found between schools high on our conventional practice scale and student achievement scores. This provides evidence that teachers' practice links the goals and results of state policy: students benefited from having teachers whose work was more closely tied to state instructional goals.

Based on this analysis, we would expect a modest relationship between many of our policy and learning indicators and student outcomes as well because the policies encouraged framework practice. This is true for our measure of teacher attendance at student curriculum-centered workshops: teachers who attended these workshops have students who performed better on the mathematics CLAS, as is evident in Equation 2 in Table 5.

A more important issue may be the effect teacher learning in the special topics/issues workshops had on student achievement. We saw earlier that this variable contributed little to explaining differences among teachers' Framework or conventional mathematics practice. Hence, any effect we might find on student achievement would be through pathways not detected by those scales, such as increasing teacher knowledge, improving equity within classrooms, or helping teachers better understand student learning. But we found no such effect of the special topics/issues workshops on student achievement. This is an important result: whatever improvements these workshops may bring to California's classrooms, they do not affect what many see as the bottom line of schooling-student performance.

The third component of the policy mix, the use of replacement units, shows a positive relationship to student achievement. Equation 3 in Table 5 shows that schools in which teachers 
Table 5

Associations Between Teachers' Practice, Their Learning Opportunities and 1994 Student Mathematics Scores on the California Learning Assessment System (CLAS)

\begin{tabular}{|c|c|c|c|c|c|}
\hline & $\begin{array}{l}\text { Equation-1 } \\
\text { CLAS }\end{array}$ & $\begin{array}{l}\text { Equation-2 } \\
\text { CLAS }\end{array}$ & $\begin{array}{l}\text { Equation-3 } \\
\text { CLAS }\end{array}$ & $\begin{array}{l}\text { Equation-4 } \\
\text { CLAS }\end{array}$ & $\begin{array}{l}\text { Equation-5 } \\
\text { CLAS }\end{array}$ \\
\hline Intercept & $2.14^{*}$ & $2.65^{\star}$ & $2.67^{*}$ & $2.66^{*}$ & $2.57^{\star}$ \\
\hline Percent of Students Eligible for Free Lunch & $-1.17^{*}$ & $-1.23^{*}$ & $-1.21^{*}$ & $-1.24^{*}$ & $-1.21^{*}$ \\
\hline School Conditions & $0.19^{*}$ & $0.17^{\star}$ & $0.17^{*}$ & $0.18^{*}$ & $0.17^{*}$ \\
\hline Framework Practice & $0.17^{*}$ & & & & \\
\hline Traditional Practice & -0.00 & & & & \\
\hline $\begin{array}{l}\text { Student Curriculum-Centered } \\
\text { Workshops - Time }\end{array}$ & & $0.065^{\star}$ & & & $0.041^{* *}$ \\
\hline Special Topics/Issues Workshops - Time & & 0.03 & & & \\
\hline Replacement Units - Average Number Used & & & $0.11^{*}$ & & $0.11^{*}$ \\
\hline Learned About CLAS & & & & $0.21^{*}$ & $0.15^{\star *}$ \\
\hline Past Framework Learning & & 0.11 & & & 0.14 \\
\hline R2 (adjusted) & 0.60 & 0.60 & 0.61 & 0.60 & 0.62 \\
\hline
\end{tabular}

Note: All survey-based measures are averages from the teachers within a school who responded to the survey.

* Indicates significance at $P<.05$ level.

** Indicates significance at $P<.15$ level.

reported that they each used one replacement unit had higher student test scores (by an average of approximately one quarter of a standard deviation) than schools in which no teachers reported use of replacement units.

Finally, we come to the effect on achievement associated with teacher learning about the California Learning Assessment System (CLAS). ${ }^{21}$ The coefficient on Learned about CLAS (Equation 4 in Table 5) suggests a clear effect: when comparing student achievement scores, schools where all teachers learned about the CLAS had higher student test scores (roughly onequarter of a standard deviation higher) than schools where no teachers learned about CLAS.
We might ask whether one of these policy initiatives is dominant in improving student scores, or whether they work independently, each exerting its own influence. It appears, based on Equation 5 in Table 5, that they work independently: each continues to contribute to higher student test scores, even when controlling for the others. In other words, California's instructional policies have cumulative effects on student learning.

Our practice and policy measures related positively to student achievement. Although this interpretation is based on aggregate data, it is difficult to think of any other reasonable inference save that teachers' learning opportunities can pay off in their students' performance if the conditions of teachers' learning summarized in our model — grounded in student curriculum, connected to several elements of instruction, and extended in time-are satisfied. This suggests that well-planned state efforts to improve instruction can successfully influence not only teaching but also student learning.

\section{Conclusion}

The 1994 survey of California elementary school teachers tells us that teachers' opportunities to learn about reform do affect their practice. When these learning opportunities are focused on student curriculum that is designed to be consistent with the reforms, and that their students study, teachers report practice that is 
significantly closer to the aims of the instructional policy. In these situations, there is a consistent relationship among the following: the professional curriculum of reform; the purposes of policy, assessment and teachers' knowledge of assessment; and the student curriculum. Finally, when the assessment of students' performance is consistent with the professional and the student curriculum, teachers' learning opportunities pay off in students' math performance. These results confirm the analytic usefulness of an instructional model of instructional policy, and suggest the potent role that the education of professionals can play in improving public education.

If our analysis is correct, teaching practice and student performance are likely to improve when educational improvement is focused on learning and teaching academic content, and when curriculum for improving teaching overlaps with curriculum and assessment for students. Under such circumstances, educational policy is an instrument for improving teaching and learning. Policies that do not meet these conditions-for example, new assessments or curricula that are not accompanied by adequate learning opportunities for teachers, or professional development that is not grounded in academic content-are less likely to have constructive effects. $^{22}$

These points have important bearing for the professional development system, or perhaps, non-system. Professional development that is fragmented, that is not focused on curriculum for students, and that does not afford teachers consequential learning opportunities cannot be expected to be a constructive agent of state or local instructional policy. Yet, that seems to be the nature of most professional development in the United States today. Teachers typically engage in a variety of short-term activities that fulfill state or local requirements for professional learning, but which are rarely deeply rooted in the school curriculum or in thoughtful plans to improve teaching and learning. Our study confirms that picture, and shows further that neither teachers' practice nor students' achievement was changed by most of the professional development experienced by most California teachers. Still, large amounts of money are spent every year on just such activities. ${ }^{23}$ Our results, therefore, present a challenge to those who make policy for and practice professional development: Can they design policies, programs, and requirements that focus far more closely on improved teaching for improved student learning?

Our analysis appears to confirm arguments in favor of standards-based reform in that it broadly supports an integrated approach to school improvement - an approach that leads to the creation of better curriculum for students, that makes suitable provision for teachers to learn that curriculum, that focuses teaching on learning, and that thoughtfully links curriculum and assessment to teaching. Some examples of standards-based reform meet these criteria while others do not. Some other approaches to school improvement that do not fly the banner of standards-based reform also meet these criteria. ${ }^{24}$

The story we have related is not a story in which the efforts of state agencies carried the day. Rather, it is a story in which the related actions of government and professional organizations were crucial. California state agencies played a key role in framing a set of ideas about improved math teaching and learning, in supporting those ideas, and in changing some state education requirements to be more consistent with the ideas. The state alone, however, did not have the educational resources to frame those ideas. This required extensive help from educators - through agencies as diverse as the National Council of Teachers of Mathematics and its California affiliate, home-office curriculum developers, and university schools and departments, among others. Changes in teaching practice depended on professional as much as state action. ${ }^{25}$

Working together, this diverse set of agents was able to create somewhat more coherent relationships among teachers' learning opportunities, their practice, school curriculum and assessments, and student achievement, than are typical in the U.S. And, our evidence shows that California reformers, after years of hard work, were able to do so for only fifteen to twenty percent of the state's teachers. The obstacles fit with what we know about fragmentation in the U.S. public education system: it is more nearly a non-system, a sprawling organization that makes it difficult to organize coherent and concerted action within even a single modest-sized school district, let alone an entire state. ${ }^{26}$

These findings also square with recent research on teachers' learning and change: certain sorts of learning opportunities do seem to alter teachers' practice and student learning, but change typically occurs slowly and partially. The teachers who took most advantage of new learning opportunities blended new elements into their practice while reducing their reliance on, but not abandoning, some older practices. 
A final note: All of our findings rest on non-experimental evidence which is not conclusive. The relationships that we have reported should be investigated with a larger population of schools and teachers, in a longitudinal format, so that more robust causal attributions might be probed, and more precise measures employed. We expect to organize such a study.

But the results that we report here do not come from left field: they seem reasonably robust, and are consistent with several related lines of recent research. ${ }^{27}$ Although we think better research on these issues is essential, we would be surprised if the direction of the effects we have found, and our model of causation, did not stand up in a more powerful design. Therefore, we think it would be wise for policymakers and practitioners to ground teachers' professional education more solidly in deeper knowledge of the student curriculum. When designing new curricula and assessments, we think it would be wise to make more adequate provision so teachers could learn about and from the new curricula and assessments. And we think it would be wise to offer teachers more opportunities to relate assessments to curricula, and both to pedagogy.

\section{Endnotes}

1. The State Board of Education in California, as in Texas, decides what texts are suitable for local adoption. Although local districts may use other texts, they lose some state subsidies by doing so.

2. The first year of the study was supported by an OERI grant, and the second year was supported by funds from Michigan State University's
College of Education. In the third year of the study, the Michigan State group became part of CPRE and was supported in part by CPRE's OERI grant.

3. See, for example, the Fall 1990 issue of Educational Evaluation and Policy Analysis, 12(3), published by the American Educational Research Association.

4. The survey was designed with Dr. Joan Talbert of Stanford University, and the data was collected by Dr. Talbert.

5. Thus, teachers responding to the questions about Marilyn Burns workshops may have studied one of her replacement units or attended a Marilyn Burns Institute.

6. In EQUALS and cooperative learning workshops, it is common for teachers to engage in mathematical activities which they may try out later in their classrooms. It is important, however, to distinguish between these activities, which tend to be short exercises intended to motivate students or introduce a topic, from the more complete curriculum module provided in a replacement unit.

7. J.W. Little (1993). "Teachers professional development in a climate of educational reform." Educational Evaluation and Policy Analysis, 15, 129-151; B. Lord (1994). “Teachers' professional development: Critical colleagueship and the role of professional communities." In N. Cobb (Ed.), The Future of Education: Perspectives on National Standards in Education (pp. 175-204). New York: College Entrance Examination Board; J. O'Day and M. Smith (1993). "Systemic reform and educational opportunity." In S.H. Fuhrman (Ed.), Designing Coherent Education
Policy: Improving the System (pp. 250-312). San Francisco: Jossey-Bass; I. Weiss (1994). A Profile of Science and Mathematics Education in the United States: 1993. Chapel Hill: Horizon Research, Inc.

8. D.L. Ball and S.S. Rundquist (1993). "Collaboration as context for joining teacher learning with learning about teaching." In Teaching for Understanding: Challenges for Policy and Practice (pp. 13-42). San Francisco: Jossey-Bass; R.M. Heaton and M. Lampert (1993). "Learning to hear voices: Inventing a new pedagogy of teacher education." In Teaching for Understanding: Challenges for Policy and Practice. San Francisco: Jossey-Bass; S.J. McCarthy and P.L. Peterson (1993). In M. McLaughlin and J. Talbert (Eds.), Teaching for Understanding: Challenges for Policy and Practice (pp. 43-83). San Francisco: Jossey-Bass; S.M. Wilson, C. Miller, and C. Yerkes (1993). "Deeply rooted change: A tale of teaching adventurously." In M. McLaughlin and J. Talbert (Eds.), Teaching for Understanding: Challenges for Policy and Practice (pp. 84-129). San Francisco: JosseyBass; D. Schifter and C.T. Fosnot (1993). Reconstructing Mathematics Education. New York: Teachers College Press.

9. The coefficients in Tables 3, 4, and 5 represent the effect associated with each variable on teachers' practice while holding all other variables constant. These controls also help control for selection effects, although a more proper control is the two-stage least squares summarized in endnote 13.

10. The variable for the special topics/ issues workshops has nearly a zero regression coefficent in both cases. 


\section{Little (1993); Lord (1994).}

12. Little (1993); M.W. McLaughlin (1991). "Enabling professional development: What have we learned?" In A. Lieberman and L. Miller (Eds.), Staff Development for Education in the '90s. (pp. 61-82). New York: Teachers College Press.

13. We performed a two-stage least squares to further control for possible teacher selection into workshops. To do this, we predicted whether teachers attend student curriculum workshops based on their reports of their administrator's support for the Frameworks, whether or not they were familiar with and liked the new standards themselves, and whether or not they attended a regional or local mathematics meeting. We then determined the effect on student curriculum workshops was washed out to be substituting these predictive values for workshop attendance for those reported by teachers. The size of the coefficient on the student curriculum workshop variable stayed the same.

14. By size we mean that the simple effect associated with a teacher attending a student curriculumcentered workshop or not was about three-quarters of a standard deviation of Framework practice, and about four-tenths of a standard deviation in traditional practice. This effect was not matched by the impact of administering CLAS, which has an impact of only about two-tenths of a standard deviation on the practice scale.

15. D.K. Cohen and D.L. Ball (1990). "Policy and practice: An overview." Educational Evaluation and Policy Analysis, 12(3).
16. R. Perry (1996). "The role of teachers' professional communities in the implementation of California mathematics reform." (p. 87). Unpublished doctoral dissertation, Stanford University.

17. Because the test was administered in the spring of 1994, roughly six months before this survey, our estimates of teachers' learning opportunities and practice corresponded in time with the assessment. To the extent that teachers' workshop learning occurred in the summer of 1994 (after the test) we underestimated the effect of these workshops on student learning.

18. The measure of socio-economic status is based on the 1991 state report of percent of students eligible for free lunch in each school; the measure of school conditions included teacher reports of parental support, student turnover and the condition of facilities; and the measure of replacement curriculum units used was based on the average of teacher reports of the number of replacement units they used.

19. We did not enter two separate variables showing whether and how long teachers attended the learning opportunities, as we did in the practice analysis, because, for the purposes of this investigation, the second captures the information of the first.

20. This variable is under-specified, but excluding it biases the coefficients on the remaining variables because teachers with some past opportunities to learn would be marked as zero, thus throwing the baseline off.

21. We tried both "Learned about CLAS" and "CLAS useful" in this model, because both could be measures of teachers' attempts to prepare students for the test. "CLAS useful" was not significant, and evidenced colinearity with "Framework practice."

22. Efforts to improve schools typically have focused only on one or another of the influences that we have discussed. Challenging curricula have failed to influence broadly teaching and learning, at least in part, because teachers had few opportunities to learn and improve their practice (see P.B. Dow, 1991. School Politics: Lessons from the Sputnik Era. Cambridge: Harvard University Press). Countless efforts to change teachers' practices through various types of professional development have been unrelated to central features of the curriculum that students would study, and have resulted in no evidence of effect on students' learning. Many efforts to drive instruction by using high-stakes tests have failed either to link the tests to the student curriculum or to offer teachers substantial learning opportunities. These and other interventions assume that working on one of the many elements that shape instruction will affect all the others. But, without rational relationships among at least several of the key influences, that assumption seems likely to remain unwarranted.

23. J.W. Little (1989). "District policy choices and teachers' professional development opportunities." Educational Evaluation and Policy Analysis, 11(2), 165-179.

24. Success for All, for example, embodies this coherence.

25 . We profited from reading portions of Suzanne Wilson's book manuscript about educators learning in and from the California reforms. 
26. D.K. Cohen and J.P. Spillane (1992). "Policy and practice: The relations between governance and instruction.” In S.H. Fuhrman (Ed.), Designing Coherent Education Policy: Improving the System, (pp. 3595). San Francisco, Jossey-Bass.

27. D. Wiley and B. Yoon (1995). "Teacher reports of opportunity to learn: Analyses of the 1993 California learning assessment system." Educational Evaluation and Policy Analysis, 17(3), 355-370 and in C.A. Brown, M.S. Smith, and M.K. Stein (1996). "Linking teacher support to enhanced classroom instruction." Paper presented at the annual meeting of the American Educational Research Association, New York, NY.

\section{Acknowledgments}

The research reported in the issue of CPRE Policy Briefs is part of a continuing study of the origins and enactment of educational reforms, and their effects. The study began in 1988, led by Deborah Loewenberg Ball, David K. Cohen, Penelope Peterson, and Suzanne Wilson, and it involved an extended group of associated researchers at Michigan State University. The research was supported by a grant (No. OERI-R308A60003) to the Consortium For Policy Research in Education (then at Rutgers, The State University of New Jersey), from the National Institute on Educational Governance, Finance, Policymaking and Management, Office of Educational Research and Improvement, U.S. Department of Education, and by grants from the Carnegie Corporation of New York, and The Pew Charitable Trusts, to Michigan State University. We are grateful to these agencies, but none is responsible for the views presented here.

The authors would like to thank Richard Murnane of Harvard University and others for their useful comments on early drafts of the research report, "Instructional Policy and Classroom Performance: The Mathematics Reform in California," the basis of this issue of CPRE Policy Briefs.

\section{About the Authors}

David K. Cohen is John Dewey Collegiate Professor of Education, and Professor of Public Policy at the University of Michigan. In addition to his current work on educational policy and the relationships between policy and practice, his previous research includes studies on the effects of schooling, efforts to reform teaching, evaluation of educational experiments and largescale intervention programs, and relations between research and policy.

Heather C. Hill is a doctoral candidate in the Department of Political Science at the University of Michigan. In addition to her current work with David $\mathrm{K}$. Cohen on mathematics reform in California, she is completing her dissertation on the role nongovernmental resources play in teaching enactors about public policy and changed educational practices.

\section{More on the Subject}

Copies of David Cohen and Heather Hill's full-length report, "Instructional Policy and Classroom Performance: The Mathematics Reform in California," will be published as a CPRE Research Report in Winter 1997; the cost is \$12.00.

To obtain copies, write:

CPRE Publications

Graduate School of Education

University of Pennsylvania

3440 Market Street, Suite 560

Philadelphia, PA 19104-3325

Make checks payable to Trustees of the University of Pennsylvania. 


\section{Recent CPRE Publications}

\section{Persistence and Change: Standards-based Reform in Nine States}

Diane Massell, Michael Kirst, and Margaret Hoppe (No. RR-037, April 1997) \$10

This report explores the persistence and transformation of standards-based instructional guidance strategies, and the issues and challenges that states and districts have confronted as they tried to implement these policies. It is based on extensive interviews conducted during 1994-95 in 9 states-California, Connecticut, Florida, Georgia, Kentucky, Minnesota, New Jersey, South Carolina and Texas, and 25 districts in those states. Please note: A Policy Brief based upon this report is available from CPRE free of charge. To obtain, please write to CPRE, referencing RB-21, at the address below.

\section{Public Policy and School Reform: A Research Summary}

(No. RR-036, March 1996) \$5

Standards-based reforms and increased professional development focused on content have helped to improve schooling and boost student achievement. But policymaking still suffers from unrealistic expectations, too much emphasis on structural change, and not enough attention to factors directly linked to student achievement. This summary attempts to highlight promising strategies and policy initiatives while helping policymakers avoid past pitfalls. The report addresses topics including standards-based reform, restructuring, policy and classroom practice, capacity, school finance, and educational productivity.

\section{Rethinking the Allocation of Teaching Resources: Some Lessons from High Performing Schools} (No. RR-038, November 1997) \$12

Although a great deal of debate surrounds the level and allocation of resources to public schools, very little of this discussion addresses how schools might organize teaching resources more effectively at the school level. This paper describes case studies of five high performing public schools that have organized professional resources in innovative ways. The study sought to detail alternative ways of deploying instructional resources in order to provide concrete alternatives to traditional organization of teachers and to quantify objectively the ways in which these schools use resources differently depending on their instructional goals and strategies. Although the schools studied looked very different from one another, they shared five principles of resource allocation which are outlined in this paper. The paper develops a framework for re-examining the use of resources and a methodology which may be used to measure the extent to which schools use their resources in focused ways to support teaching and learning.

Teacher Professional Development Profiles, a product of CPRE's 50-state study on professional development, are available through the Consortium for Policy Research in Education. Designed to provide an information base for state policymakers interested in improving teacher learning opportunities, these profiles are useful for stimulating discussion about professional development. Please call 215-573-0700, and then press 1 for pricing information.

\section{Ordering Information}

To obtain copies of these publications, write: CPRE Publications, Graduate School of Education, University of Pennsylvania, 3440 Market Street, Suite 560, Philadelphia, PA 19104-3325. All orders must be prepaid with U.S. funds drawn from U.S. banks; make checks payable to Trustees of the University of Pennsylvania. Please note: sales tax is not applicable. Sorry, we cannot accept returns, credit card orders, or purchase orders.

To obtain copies of CPRE Policy Briefs, write to the address above or email us at cpre@gse.upenn.edu. There is no charge for single copies. 


\section{About CPRE}

The Consortium for Policy Research in Education (CPRE) unites five of the nation's leading research institutions in an exciting venture to improve student learning through research on education policy, governance, and finance. Members of CPRE are the University of Pennsylvania; Harvard University; Stanford University; the University of Michigan; and the University of Wisconsin-Madison.

CPRE conducts research on issues such as:

- education reform

- student and teacher standards

- state and local policymaking

- education governance

- school finance

- teacher compensation

- student incentives

To learn more about CPRE or CPRE publications, please call 215/573-0700. CPRE's home page can be found at:

\section{Nondiscrimination Statement}

The University of Pennsylvania values diversity and seeks talented students, faculty and staff from diverse backgrounds. The University of Pennsylvania does not discriminate on the basis of race, sex, sexual orientation, religion, color, national or ethnic origin, age, disability, or status as a Vietnam Era Veteran or disabled veteran in the administration of educational policies, programs or activities; admissions policies, scholarships or loan awards; athletic, or University administered programs or employment. Questions or complaints regarding this policy should be directed to Executive Director, Office of Affirmative Action, 1133 Blockley Hall, Philadelphia, PA 19104-6021 or (215) 8986993 (Voice) or (215) 898-7803 (TDD).

\section{http://www.upenn.edu/gse/cpre/}

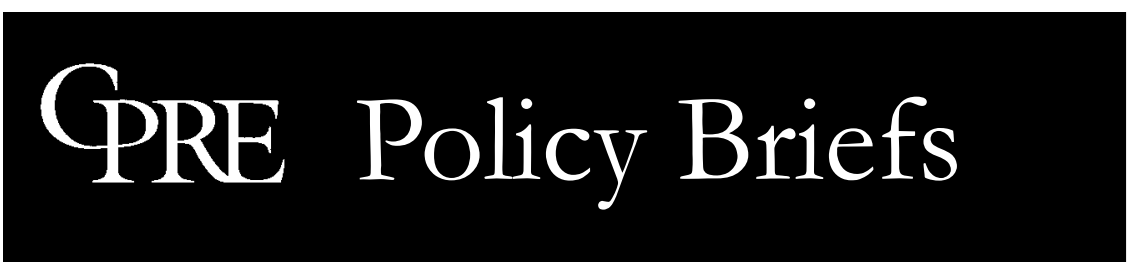

NON PROFIT

U.S. POSTAGE

PAID

PERMIT NO. 2563

PHILADELPHIA, PA

Graduate School of Education

University of Pennsylvania

3440 Market Street, Suite 560

Philadelphia, PA 19104-3325 